\title{
Lactate Production of Mammalian Intestinal and Vascular Smooth Muscles Under Aerobic and Hypoxic Conditions
}

\author{
Yukisato IsHIDA and Keiko TAKAGI-OHTA \\ Mitsubishi Kasei Institute of Life Sciences, \\ Machida, Tokyo 194, Japan
}

\begin{abstract}
Lactate liberation from thoracic aortas and intestinal smooth muscles of the guinea pig, rabbit and rat, as well as coronary arteries of the dog were determined under aerobic and hypoxic conditions ( $95 \% \mathrm{~N}_{2}$ instead of $\mathrm{O}_{2}$ ). In all smooth muscles tested, the lactate liberation was inhibited in the presence of oxygen, being known as the Pasteur effect. The rates of lactate release from guinea pig aortas and taenia caeci under hypoxia were approximately 10 times greater than those under aerobic conditions. The rate of lactate release from other smooth muscles tested were 3-4 times greater under hypoxic than aerobic conditions. The extent of Pasteur effect was not affected by a removal of adventitial layer from the rabbit aorta nor by the different size of the dog coronary arteries. These results suggest that taenia caeci and aortas of the guinea pig intrinsically possess a strong regulatory system in the glycolytic activity, being highly sensitive to the presence of oxygen.
\end{abstract}

Key words: lactate, hypoxia, vascular and intestinal smooth muscles

\section{Introduction}

The rate of lactate production of cells is high in anaerobic conditions and low in aerobic conditions, being so called as "Pasteur effect" (Krebs, 1972). In some tissues such as intestinal mucosa, jejunum, renal medulla, erythrocytes, retina, etc., the lactate production is not reduced in the presence of oxygen and thus the high rate of aerobic glycolysis takes place in those cells (Krebs, 1972). Also, in vascular smooth muscles, a relatively weak Pasteur effect has been considered as characteristics of their metabolism: rates of lactate release from various vascular smooth muscles are 3-4 times faster in anaerobic than in aerobic conditions (Paul, 1980). On the other hand, in the intestinal smooh muscle of guinea pig taenia caeci, the extent of anaerobic lactate production was approximately 10 times greater than that of aerobic lactate production (Casteels and Wuytack, 1975 ; Ishida, et al., 1984 ; Ishida and Paul, 1990). In the present experiments, in order to ascertain the high ratio of lactate production under hypoxic to aerobic conditions in guinea pig smooth muscle, the extent of Pasteur effect was

Correspondence to: Yukisato Ishida. Mitsubishi Kasei Institute of life Sciences, 11 Minamiooya, Machida, Tokyo 194, Japan. 
compared between vascular and intestinal smooth muscles of various species such as guineapig, rabbit, rat and dog. A characteristically high extent of Pasteur effect is demonstrated in aortas and taenia caeci of the guinea pig but not in smooth muscles of other species tested.

\section{Methods}

\section{Smooth muscle preparations}

Vascular and intestinal smooth muscles were isolated from male albino rabbits (1.5-2 kg), guinea pigs (300-400 g) and Wister rats (250-350 g). Animals were stunned and bled except dogs which were killed by an i.v. injection of pentobarbital $(50 \mathrm{mg} / \mathrm{kg})$.

Thoracic aortas were isolated from rabbit, guinea pig and rat. From dog, coronary arteries of the left circumflex and the adjacent second branch from the proximal of left circumflex were isolated. Excess fat and connective tissues were removed from blood vessels. Vessels were cut open longitudinally and rectangular strips were made. In a part of experiments, the adventitial layer of the rabbit aorta and the endothelial cells were removed as described by Karaki and Urakawa (1976) and (Hashimoto et al., 1993), respectively. Strips of rabbit taenia coli and guinea pig taenia caeci were prepared. Rat coli were cut open longitudinally and rectangular strips were made. Each smooth muscle preparation was approximately $10 \mathrm{mg}$ in wet weight.

Muscles were placed in an oxygenated physiological salt solution $\left(37^{\circ} \mathrm{C}\right)$ for $60 \mathrm{~min}$ and weighted on an electronic balance (Sauter AR-1014, Germany). Then, each muscle was attached to a glass rod and equibibrated in the oxygenated solution at least for another $60 \mathrm{~min}$ before starting experiments. The physiological salt stlution contained $\mathrm{NaCl} 136.8, \mathrm{KCl} 5.4$, $\mathrm{CaCl}_{2} 2.5, \mathrm{MgCl}_{2}$ 1.0, $\mathrm{NaHCO}_{3} 11.9$ and glucose $5.6(\mathrm{mM})$ and bubbled with $95 \% \mathrm{O}_{2}: 5 \% \mathrm{CO}_{2}$ for aerobic conditions or $95 \% \mathrm{~N}_{2}: 5 \% \mathrm{CO}_{2}$ for hypoxic conditions.

\section{Lactate determination}

The amount of lactate released from the muscle was determined by a combination of lactate dehydrogenase and bacterial luciferase, as reported previously (Ishida, et al., 1984). Muscles were incubated in $2 \mathrm{ml}$ of solutions and transferred to the next solution successively every $15 \mathrm{~min}$. The solution was pre-equilibrated with aerobic or hypoxic conditions. Promptly after the termination of the incubation, $0.2 \mathrm{ml}$ of the incubated solution was subjected to analyze the amount of lactate. The released amount of lactate was nearly constant after 15 min exposure of the muscle to hypoxic conditions and was greater than that during initial 15 min exposure to hypoxa. Thus, rates of lactate release from the muscle under hypoxia in table 2 were estimated by the amount of lactate released between $15 \mathrm{~min}$ and $30 \mathrm{~min}$ after the imposition of hyoxia.

\section{Results}

Lactate production in aortas and taenia caeci of guinea pig

Figure 1 shows the amount of lactate released from guinea pig aortas and taenia caeci 


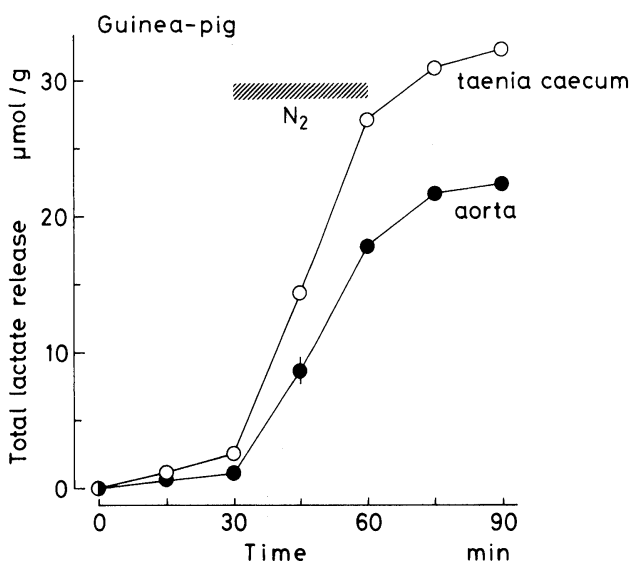

Fig. 1. Amount of lactate released under aerobic and hypoxic conditions in the guinea pig aortas $(\bullet)$ and taenia caeci $(\bigcirc)$. Aerobic and hypoxic conditions were made by bubbling $95 \% \mathrm{O}_{2}: 5 \% \quad \mathrm{CO}_{2}$ and $95 \% \quad \mathrm{~N}_{2}: 5 \%$ $\mathrm{CO}_{2}$, respectively. In the ordinate, cumulative amounts of released lactate were plotted. Vertical bar represents s.e.m. $(n=6)$. Symbols without the bar means that s.e.m. is smaller than the size of symbol. Each muscle was successively transferred from one test tube to another every $15 \mathrm{~min}$.

under aerobic (95\% $\mathrm{O}_{2}$ bubbled) and hypoxic conditions (95\% $\mathrm{N}_{2}$ instead of $\mathrm{O}_{2}$ ), when muscles were transferred successively from one solution to another every $15 \mathrm{~min}$ as described previously (Ishida and Paul, 1990). In aerobic conditions, both smooth muscle preparations released lactate with constant rates of $39 \mathrm{nmol} / \mathrm{min} / \mathrm{g}$ wet weight in aortas and $86 \mathrm{nmol} / \mathrm{min} / \mathrm{g}$ in taenia caeci (Table 2). When these muscle preparations were exposed to hypoxic conditions, rates of lactate release promptly increased to 493 and $835 \mathrm{nmol} / \mathrm{min} / \mathrm{g}$ in aortas and taenia caeci, respectively. The lactate release rate under hypoxia was 9.8 or 12.8 times greater than that under aerobic conditions in aortas or taenia caeci, respectively.

When oxygen was readmitted after hypoxic conditions (reoxygenation), rates of lactate release in aoras and taenia caeci were gradually reduced and attained the original values in 15 min after the reoxygenation (Fig. 1). Thus, the effect of hypoxic conditions on lactate production in guinea pig smooth muscles tested appears to be reversible. The similar reversible effect of hypoxic conditions on lactate production was observed in rabbit aortas and taenia coli (data not shown).

The effect of rexogenation on the amount of lactate accumulated in the external solution

Table 1. Amounts of lactate released from the guinea pig taenia caeci during prolonged exposure to aerobic, hypoxic and reoxygenated conditions.

\begin{tabular}{c|c}
\hline Incubation conditions & $\begin{array}{c}\text { Released lactate } \\
(\mu \mathrm{mol} / \mathrm{g} \text { wet weight })\end{array}$ \\
\hline Aerobic conditions for $60 \mathrm{~min}$ & $8.79 \pm 0.90$ \\
Hypoxic conditions for $60 \mathrm{~min}$ & $70.25 \pm 4.33$ \\
Reoxygenation for $60 \mathrm{~min}$ after \\
hypoxic conditions for $60 \mathrm{~min}$
\end{tabular}

Values are expressed as mean \pm s.e.m. $(n=6)$. Throughout the experimental protocol indicated, each muscle was incubated in a test tube containing $2 \mathrm{ml}$ of a physiological salt solution bubbled with $95 \% \mathrm{O}_{2}: 5 \% \mathrm{CO}_{2}$ or $95 \% \mathrm{~N}_{2}: 5 \% \mathrm{CO}_{2}$ for aerobic or hypoxic conditions, respectively. Reoxygenation was performed by simply switching $95 \% \mathrm{~N}_{2}$ over to $95 \% \mathrm{O}_{2}$. 
during a prolonged incubation of the guinea pig taenia caeci was examined (Table 1). When the muscle was exposed to hypoxic conditions for $60 \mathrm{~min}$ in a test tube with $2 \mathrm{ml}$ of solution, lactate was accumulated in the external solution and the accumulated amount was approximately 10 times greater in hypoxic conditions than that in the aerobic condition, which is consistent to the above results described. Reoxygenation for $60 \mathrm{~min}$ did not elicit a significant change in the accumulated amount of lactate after the 60 min exposure of the muscle to hypoxic conditions. Endo et al. (1989) reported that in the guinea pig taenia caeci lactate can be a substrate for oxidative phosphorylation, though less effective when compared with glucose. They further reported that, when lactate was added to the glucose-depleted solution, the half maximum effective concentration of lactate in the external solution may be $\sim 3.5 \mathrm{mM}$. In the present experiments, assuming $10 \mathrm{mg}$ of the taenia caeci is incubated in $2 \mathrm{ml}$ of the solution, the external concentration of lactate after $60 \mathrm{~min}$ exposure to hypoxic conditions may reach only $\sim 0.5 \mathrm{mM}$ in addition to the presence of $5.6 \mathrm{mM}$ glucose. Therefore, lactate accumulated into the hypoxic solution for $60 \mathrm{~min}$ in the presence of glucose may not be much available for ATP production of the taenia caeci and lactate may fuel the oxidative metabolism in the glucosedeficient conditions.

Comparison of lactate release rate among various smooth muscle

Table 2 shows the lactate release rate from intestinal and vascular smooth muscles

Table 2. Rates of lactate release from vascular and intestinal smooth muscles under aerobic $\left(95 \% \mathrm{O}_{2}: 5 \% \mathrm{CO}_{2}\right)$ and hypoxic conditions $\left(95 \% \mathrm{~N}_{2}: 5 \% \mathrm{CO}_{2}\right)$.

\begin{tabular}{|c|c|c|c|c|}
\hline & \multicolumn{2}{|c|}{$\begin{array}{l}\text { Rate of lactate release } \\
(\mathrm{nmol} / \mathrm{min} / \mathrm{g} \text { wet } \mathrm{wt})\end{array}$} & \multirow{2}{*}{$\begin{array}{l}\text { Ratio } \\
(\mathrm{B} / \mathrm{A})\end{array}$} & \multirow{2}{*}{$\begin{array}{c}\text { Pasteur effect } \\
(\%) \\
(1-\mathrm{A} / \mathrm{B}) \times 100\end{array}$} \\
\hline & aerobic $(\mathrm{A})$ & hypoxic (B) & & \\
\hline \multicolumn{5}{|l|}{ Guinea pig } \\
\hline aortas & $39 \pm 4$ & $493 \pm 68$ & $12.8 \pm 1.14$ & $92.1 \pm 0.67$ \\
\hline taenia caeci & $86 \pm 1$ & $835 \pm 22$ & $9.8 \pm 0.16$ & $89.7 \pm 0.17$ \\
\hline \multicolumn{5}{|l|}{ Rat } \\
\hline aortas & $136 \pm 11$ & $505 \pm 25$ & $3.7 \pm 0.14$ & $73.1 \pm 1.02$ \\
\hline coli & $168 \pm 12$ & $695 \pm 42$ & $4.2 \pm 0.05$ & $76.5 \pm 0.29$ \\
\hline \multirow{2}{*}{\multicolumn{5}{|c|}{$\begin{array}{l}\text { Rabbit } \\
\text { aortas }\end{array}$}} \\
\hline & & & & \\
\hline intact & $56 \pm 7$ & $188 \pm 7$ & $3.6 \pm 0.32$ & $71.6 \pm 2.73$ \\
\hline adventitia-removed & $92 \pm 3$ & $328 \pm 4$ & $3.5 \pm 0.12$ & $71.7 \pm 0.97$ \\
\hline taenia coli & $82 \pm 3$ & $342 \pm 13$ & $4.2 \pm 0.15$ & $75.9 \pm 0.87$ \\
\hline \multicolumn{5}{|l|}{ Dog } \\
\hline coronary artery & & & & \\
\hline left circumflex & $149 \pm 20$ & $380 \pm 26$ & $2.6 \pm 0.17$ & $60.7 \pm 0.58$ \\
\hline second branch & $200 \pm 26$ & $500 \pm 24$ & $2.6 \pm 0.23$ & $62.3 \pm 1.33$ \\
\hline
\end{tabular}

Values are expressed as mean \pm s.e.m. $(n=3 \sim 6)$. Rabbit aortas were divided into two groups: intact and adventitial layer-removed (adventitia-removed) preparations. In dog coronary arteries, left circumflex and its adjacent second descending branch (second branch) were tested. 
prepared from guinea pig, rat, rabbit and dog under aerobic and hypoxic conditions. Under aerobic conditions, the rate of lactate release from the tissue ranged from 40 (guinea pig aorta) to $200 \mathrm{nmol} / \mathrm{min} / \mathrm{g}$ wet weight (dog coronary artery, second branch). Under anaerobic conditions, the range of lactate release rate was 190 (rabbit intact aorta) $-840 \mathrm{nmol} / \mathrm{min} / \mathrm{g}$ (guinea pig taenia caeci). In the present experiments, the lactate release rate was greater in the intestinal smooth muscle than in the vascular smooth muscle of the same species tested under both aerobic and hypoxic conditions. A removal of adventitial layer from aorta of the rabbit elevated the lactate release rates to the values nearly equivalent to those of the rabbit taenia coli under aerobic and hypoxic conditions. In the dog coronary artery, the small artery of the second branch from the left circum flex released more lactate than the big artery of left circum flex.

In all smooth muscle preparations tested, the lactate production is inhibited in the presence of oxygen, which is known as the Pasteur effect. Although the ratio of lactate release rate under hypoxic to aerobic conditions may be an index of Pasteur effect, the extent of Pasteur effect is alternatively estimated from the percent inhibition of Pasteur effect in the rate of lactate release (\% of Pasteur effect), using the following equation (Wenner, 1989) :

(1-the release rate in aerobic conditions/the rate in hypoxic conditions) $\times 100$. The last column of table 2 shows \%s of Pasteur effect in the smooth muscle preparations tested. The nearly same extents of Pasteur effect were observed in vascular and intestinal smooth muscles of the same species. Values of \% Pasteur effect were high (approximately 90\%) in smooth muscles of the guinea-pig, medium (70-75\%) in those of rat and rabbit, and low (approximately $60 \%$ ) in coronary arteries of the dog. Removal of adventitial layer from the rabbit aorta did not alter the extent of Pasteur effect. Either, the regional difference was not present in the Pasteur effect of the dog coronary artery.

\section{Discussion}

When arterial and intestinal smooth muscles of the guinea pig, rat and rabbit as well as dog coronary arteries were exposed to hypoxic conditions, their lactate production increased promptly, indicating that the Pasteur effect takes place in smooth muscles tested in the present experiments. Particularly, in the guinea pig, not only the taenia caeci but also thoracic aortas showed a markedly high ratio $(\sim 10)$ of hypoxic to aerobic lactate production rate, being almost equivalent to those reported in the rat liver and brain cortex (Warburg, 1926 ; Burk, 1939). Other tested vascular and intestinal smooth muscles of the rat, rabbit and dog had a relatively week extent of Pasteur effect: the ratio of hypoxic to aerobic lactate production rate was 34 which is well in a comparable range as reported previously (review : Paul, 1980). Therefore a characteristically high extent of Pasteur effect occurs in the aortas and taenia caeci of the guinea pig.

Distributions of cellular water in the intact rabbit aorta and rabbit taenia coli were 26.3 and $37.1 \%$ of the tissue wet weight, respectively, suggesting that the content of the conective tissue is greater in the aorta than in the taenia coli (Jones et al., 1973). In the rabbit the difference of lactate release rates between aortas and taenia coli (ratio of aorta/taenia, 0.68) was nearly 
coincident with the difference of cellular water space (ratio, 0.71). A removal of adventitial layer from intact aortas apparently increased the rates of lactate production under both aerobic and hypoxic conditions up to similar values of the rabbit taenia coli on the basis of the tissue wet weight. Since the adventitial layer is rich in connective materials, its removal increased the proportion of smooth muscle cells in the tissue, thus leading to the apparent increase in the lactate production. Presumably, this proportional increase in smooth muscle cells in a tissue accounts for the regional difference of the lactate production rates observed in the dog coronary artery. The left circumflex of the coronary artery has a greater diameter than the second descending branch. The large artery might contain more connective materials than the small artery, as described by Jones (review, 1980). Thus, the left circum flex had a lower rate of lactate production than the second descending branch, based on the tissue wet weight.

When oxygen is insufficiently supplied to cells, a bigger amount of lactate is released from cells even in aerobic conditions, presumably leading to the lower extent of Pasteur effect. Presumably, oxygen accesses more readily to the adventitial layer-removed aorta than to the intact aorta, and to the small artery than to the large artery. However, the removal of adventitial layer from rabbit aorta did not affect the extent of Pasteur effect. Also, the extent of Pasteur effect was same between large and small coronary arteries of the dog. These results suggest that the low extent of Pasteur effect in arterial smooth muscles is not due to the less availability of oxygen to smooth muscle cells.

High activity of aerobic glycolysis has been argued to provide a low extent of Pasteur effect in vascular smooth muscle (Paul, 1980) and other tissues such as retina, jejunum, etc. (Krebs, 1972 ; Ramaiah, 1974 ; Tejwani, 1978). In aortas and coli of rat and coronary arteries of $\mathrm{dog}$, the rate of lactate release under aerobic conditions $(>100 \mathrm{nmol} / \mathrm{min} / \mathrm{g}$ ) was apparently greater than those of other smooth muscles tested. The cellular space of rat aorta was reported to be $20.8 \%$ of the wet weight which was much smaller than that $(47.7 \%)$ of guinea pig taenia caeci (Jones, 1980). Therefore, high aerobic glycolysis accounts for the low extent of Pasteur effect in tested smooth muscles of the rat as well as the dog.

Guinea pig aortas were revealed to release lactate with a low rate $(\sim 40 \mathrm{nmol} / \mathrm{min} / \mathrm{g})$ under aerobic conditions, being approximately $1 / 3$ of rat aortas. Under hypoxic conditions, the rates of lactate production were almost same in both aortas of the guinea pig and rat $(\sim 500 \mathrm{nmol} /$ $\mathrm{min} / \mathrm{g}$ ). Thus, the high extent of Pasteur effect in the guinea pig aorta is mainly attributed to the low rate of lactate production.

The high extent of Pasteur effect was also observed in the guinea pig taenia caeci. The taenia caeci released lactate with a relatively low rate $(\sim 90 \mathrm{nmol} / \mathrm{min} / \mathrm{g})$ under aerobic conditions in spite of the relatively large cellular space, and with a highest rate $(\sim 850 \mathrm{nmol} /$ $\mathrm{min} / \mathrm{g}$ ) under hypoxic conditions among tested smooth muscles. These results indicate that the high extent of Pasteur effect in the guinea pig taenia caeci is derived from absolute values of low and high rates of lactate production under aerobic and hypoxic conditions, respectively. On the other hand, under aerobic conditions, rabbit aortas and taenia coli released lactate with comparable rates to those of guinea pig aortas and taenia caeci. However, in rabbit smooth muscles, imposition of hypoxic conditions augmented lactate production rates only 4 times, not 10 times, of those under aerobic conditions. Therefore, taenia caeci and aortas of the guinea 
pig may intrinsically possess a strong regulatory system in the glycolytic activity, being highly sensitive to the presence of oxygen, although the cellular or molecular mechanism for the regulatory system in glycolysis is yet known at present.

\section{References}

Burk, D. (1939). A colloquial consideration of the Pasteur and neo-Pasteur effects. Cold Spring Harb. Symp. Quant. Biol. 7 : 420-459.

Casteels, R. and Wuytack, F. (1975). Aerobic and anaerobic metabolism in smooth muscle cells of taenia coli in relation to active ion transport. J. Physiol. (Lond.) 347: 149-159.

Close, L.A., Bowman, P.S. and Paul, R.J. (1994). Effects of endothelium on metabolic and mechanical parameters in porcine coronary artery. Endothelium 1: 317-323.

Endo, I., Suzuki, T., Takahashi H. and Karaki, H. (1989). Selective utilization of L-isomer of lactate in the smooth muscle of the guinea pig taenia caeci. Can. J. Physiol. Pharmacol. 67: 15401543.

Hashimoto, M., Close, L.A., Ishida, Y. and Paul, R.J. (1993). Dependence of endothelium-mediated relaxation on exygen and metabolism in porcine coronary arteries. Am. J. Physiol. 265: H299-H306.

Ishida, Y. and Paul, R.J. (1990). Effects of hypoxia on high-energy phosphagen content, energy metabolism and isometric force in guinea-pig taenia caeci. J. Physiol. (Lond.) 424: 41-56.

Ishida, Y., Takagi, K. and Urakawa, N. (1984). Tension maintenance, calcium content and energy production of the taenia of the guinea-pig caecum under hypoxia. J. Physiol. (Lond.) 347 : 149-159.

Jones, A.W. (1980). Content and fluxes of electrolytes. In: Handbook of Physiology, sect. 2, vol. II, Cardiovascular System, ed. by D.F. Bohr, A.P. Somlyo and H.V. Sparks, American Physiolog. ical Society, Bethesda MD, pp. 253-299.

Jones, A.W., Somlyo, A.P. and Somlyo, A.V. (1973). Potassium accumulation in smooth muscle and associated ultrastructural changes. J. Physiol. (Lond.) 232 : 247-273.

Karaki, H. and Urakawa, N. (1977). Possible role of endogenous catecholamines in the contractions induced in rabbit aorta by ouabain, sodium depletion an potassium depletion. Eur. J. Pharmacol. 43 : 65-72.

Krebs, H.A. (1972). The Pasteur effect and the relations between respiration and fermentation. Essays in Biochemistry 8: 1-34.

Paul, R.J. (1980). Chemical energetics of vascular smooth muscle. In: Handbook of Physiology, sect. 2, vol. II, Cardiovascular System, ed. by D.F. Bohr, A.P. Somlyo and H.V.Sparks, American Physiological Society, Bethesda MD, pp. 201-235.

Ramaiah, A. (1974). Pasteur effect and phosphofructokinase. Curr. Top. Cell. Regul. 8: 297-345.

Tejwani, G.A. (1978). The role of phosphofructokinase in the Pasteur effect. Trends Biochem. Sci. 3 : 30-33.

Warburg, O. (1926). In: Uber den Stoffwechsel der Tumoren. Springer-Verlag, Berlin.

Wenner, C.E. (1979). Pasteur and Crabtree effects - Assay in cells. Method Enzymol. 55 : 289-297. 